\title{
Cultivation of Innovation Consciousness of Teaching Management Personnel in Colleges and Universities
}

\author{
Chunfang Wang \\ School of Humanities, Jilin Agricultural University, Changchun 130118, China \\ (E-mail: 854325524@qq.com)
}

\begin{abstract}
Key Words: Colleges and universities ; Teaching management personnel; Innovation
\end{abstract} consciousness

\begin{abstract}
The education principles of colleges and universities should be based on the education and take the teaching work as the center. The innovation consciousness of the teaching management personnel in colleges and universities is the necessary consciousness to train the qualified talents for the future society, and it is one of the abilities that the university teaching management personnel must have to adapt to the social development. This paper introduces the connotation of innovation consciousness, analyzes the characteristics of the university teaching management personnel and the reasons for lack of innovation consciousness, and puts forward some countermeasures for improving the innovation consciousness of the college teaching management personnel.
\end{abstract}

\section{Connotation of innovative consciousness}

The main features of innovative consciousness are unconventional, creative and critical, having the spirit of being unique and unorthodox. In terms of subjective factors, the basic connotation of the teaching managers' innovation consciousness should include dynamic consciousness, advanced consciousness, method consciousness and reform consciousness.

Dynamic consciousness. Look at from the perspective of innovative individuals, whether the innovator's behavior is positive or not, fundamentally, is influenced by both the physical and mental factors. That is material power and spiritual power emphasized by the behavioral science. Scientific dynamic mechanism can be created to mobilize the innovators' enthusiasm with the scientific dynamic view.

Advanced consciousness. The college teaching management personnel should have advanced consciousness when the modern science develops rapidly and the speed of knowledge updating is fast. As the staff of the school's decision-making, the teaching management personnel should have some creativity. They should put forward some new plans for the development of the school and the reform of the education, and keep on exploring and practicing. The persistent pursuit of hard will, reasonable cognitive structure and the necessary equipment tools are the necessary conditions to innovate.

Method consciousness. Unscientific thinking methods, not summing up experiences and lessons and not tracking new scientific methods to improve their thinking methods are the taboos of innovators. Thus, the thinking methods play a very important role in innovation. The teaching management personnel in colleges and universities should consciously attach importance to the method consciousness of innovation.

Reform consciousness. It is also developing consciousness and competitive consciousness. With the transformation from traditional economy to knowledge economy, the traditional information processing method cannot adapt to the "knowledge economy" system, which also determines the university teaching management personnel must have a fundamental change. That is, the management methods change from the empirical management to scientific, human-oriented management, and the technical means of management change from the manual-based management to the modern scientific and technological management that uses computers. 


\section{Characteristics of the teaching management team}

Undergraduate teaching management team includes the principals who are in charge of teaching, the full-time teaching management personnel in dean's office, the director of the college and the chairman of the department who are in charge of teaching, educational management personnel and teaching secretary in the college and department. Therefore, the personnel who are responsible for teaching management in higher education institutions can be divided into two levels: one is the leadership in charge of teaching, such as the principal who is responsible for teaching, the dean of the dean, and the dean of the faculty or the head of the college who in charge of teaching. The other is general teaching management personnel, such as the full-time teaching management personnel except the dean in dean's office, the director of the teaching office in each college and department, and the teaching secretary.

First, the source is complex and unstable, but the age structure is more reasonable. Leaders of teaching management in colleges and universities are mostly produced from the teaching team, and familiar with the teaching links and characteristics. They have a certain teaching practice and management experience. The age structure of the leadership of teaching management in colleges and universities is reasonable. With high professional titles, education and academic degrees, they are the main force of teaching management and the key to the teaching quality and management level of the whole school. In particular, most of the teaching management leaders in colleges and universities are experts in certain subjects. However, as an expert in a subject, they also engage in teaching management work, so it often happens that a person's energy is difficult to satisfy the requirement of being both the scholar and the manager. Therefore, the thing that some people are tired of handling even quit often occurs.

Second, the task is varied and arduous, and the training opportunities are few. In recent years, although the higher education develops rapidly, the expansion of student enrollment is obvious, and the number of the first-line teachers increases rapidly, but the development of teaching management team is relatively slow. Thus, the number of the general teaching management personnel has changed little and the improving of the teaching management level is not obvious. Accordingly, the general teaching management personnel's daily teaching management work is heavy and complex, and they lack training time and opportunities for further study. All of these make them lack the proper management knowledge and innovative spirit. Faced with office automation, most of them are tired of handling. In addition, the responsibility of the teaching management personnel is significant, which means they cannot have any errors in the work. If they have, the mistakes may cause confusion to the entire school, and bring the effect to the whole school students, may be thousands or tens of thousands of people, but also may cause serious property damage.

\section{Reasons for the lack of innovation consciousness in the teaching management personnel}

From the whole point of view, innovative education for teaching management personnel is good, but there is a landslide trend. Specifically, the reasons for the lack of innovation consciousness in the management personnel are as follows:

First, they follow the beaten path and make no attempt to make progress. The enterprising thinking is constrained by the great inertia of traditional work habits. University is the last fortress of China's planned economy. Many people have been accustomed to thinking and understanding the problem in accordance with the planned economy. The personnel of the teaching management in the subordinate position in college naturally cannot get rid of the impact and constraint of the outmoded ideas. Many of them still remain the traditional thinking, and they lack the sense of crisis and the sense of urgency that strengthen their own learning.

Second, the wages are somewhat low and the work is overload. The leadership and the functional department still don't give enough attention, care, understanding and support to the teaching management work. As a matter of fact, the teaching management work in colleges and universities is important, but in fact the teaching management personnel are only treated as a specific clerk, and 
the wages are also much lower than those of teachers. The overloading work make them have high physical and mental stress. They often work day and night, and are afraid of making mistakes in work. With high pressure and physical and mental exhaustion, the burnout psychology arises spontaneously. In this case, how can there be time and mood to learn, to improve themselves, and let alone being engaged in research and writing scientific research papers to meet the necessary requirements of the title evaluation. Therefore, improving their treatment will become unattainable Castle in the air.

Third, there is no plan, and the measures are also insufficient. Some colleges and universities lack long-term plans on the teaching management personnel's innovative education. Speaking of the teaching management work, although it is important, but developing the plan of talents training lacks the content of training the teaching management talents. Some leaders also don't have clear objectives and specific requirements on continuing education. Learning atmosphere is not strong, academic air is weak, even the teaching management personnel don't think they are lack of knowledge. So the motivation of learning is out of the question.

\section{Cultivation of innovation consciousness of teaching management staff in colleges and universities}

Based on the characteristics of teaching management personnel, the author believes that cultivating their innovative consciousness is the need to adapt to social development, scientific and technological progress and education and teaching reform. It is necessary to cultivate innovative talents to adapt to social development. To this end, the following four aspects of countermeasures should be taken promptly:

First, the leadership at all levels should attach importance to cultivating the innovation consciousness of the teaching management personnel. Teaching management is a science, an art, and an important guarantee to improve the quality of teaching. Leaders at all levels should pay attention to the teaching management work and the cultivation of the teaching management personnel's innovation consciousness, and commit to teaching management innovation. If the teaching management personnel are provided with the innovation consciousness, they can continue to establish a clear goal of teaching management under the strong sense of the pursuit of innovation, and always keep the passion and impulse of innovation. They also can actively and consciously engage in teaching management innovation activities, and work hard. They will make a greater contribution to protecting the teaching order and improving the quality of teaching. If the leadership at all levels of colleges and universities ignore the cultivation of the teaching management personnel's innovation consciousness, the teaching management team can not build an innovative atmosphere. Therefore, the teaching management personnel's innovation consciousness and motivation will not have, and not to mention the improvement of the teaching management level and teaching quality.

Second, a good environment is needed, and the ability of innovation should be improved continuously. The first is to create an innovative atmosphere, a new situation that innovation and innovators are glorious, and the atmosphere that "everywhere can be the place to create, every day can be the time to create and everyone can be the person to create". The next is to provide opportunities for them to practice. Let each manager have the opportunity to show themselves. At the same time, the innovative tasks in the field of teaching management, services and business developing should be given to them. Finally, the good material conditions also should be provided to them, including such as configuring modern office equipment for teaching secretary and so on.

Third, the phenomenon of "putting high value on use but not training" should be changed and the teaching management personnel's quality should be improved. Because of the heavy task, the busy work and the absence of management theory, some teaching management personnel lack further study for work, let alone innovate thinking. All of these lead to the low efficiency which not only hinders the development of the school teaching, affects the development of teaching staff but also restricts the formation of innovation consciousness of the teaching administrators. After the promotion of the teaching evaluation in recent years, although these phenomena have changed a lot, 
but it still can not meet the needs of training innovative talents in colleges and universities. Therefore, the range of knowledge of the teaching management personnel should be broaden continually through variety ways such as the visit learning, further study on pedagogical theory, education management seminars and self-study. They should improve their own quality by learning education, psychology and management knowledge to establish a knowledge-based, learning-oriented, high-quality teaching management team, and to lay a knowledge foundation for creatively completing the teaching management work.

Fourth, the competition mechanism should be strengthened to promote the growth of innovative talents. First of all, the reform of education management should be deepened, the competition mechanism should be strengthened, and the post responsibility system and appointment system should be carried out. The seniority-based system and the system of life tenure in the evaluation of professional titles also should be broken. The system that employ the people with high capacity for low position should be carried out for some business elite or the young people who has strong ability and achievements to encourage the teaching management personnel to improve themselves. Second, scientific research activities should be held widely to enhance the scientific research awareness of the management, and everyone can carry out research activities according to their own business and professional to constantly develop their creative spirit and creative ability in work. Third, the investment in education should be increased and the training should be strengthened to promote the innovation of the whole teaching management group.

\section{Conclusion}

Since the end of the century, China's higher education has entered a stage of rapid development, and has cultivated a large number of professionals for the community. At the same time, it is also faced with the status quo that the teaching management personnel have some shortcomings in the teaching management in higher education. More high-quality innovative talents are needed in century technological revolution and knowledge-intensive industries. But the scale of the colleges and universities expands rapidly, which makes the conditions of running schools is difficult to meet the needs of training high-quality talents on a large scale. So it urgently requires all levels of teaching management personnel have the innovation consciousness and establish the concept of "respecting innovation, longing for innovation, the pursuit of innovation". In the work, they should follow the people-oriented direction, open up new ideas, reform the methods and means of the teaching management, and keep pace with the times to solve the new management problems in teaching. They also should mobilize maximally the teachers' teaching enthusiasm and the students' study enthusiasm, guide teachers to carry out educational innovation and innovative education, and establish a more scientific and standardized teaching management system and quality assurance system. They should create a good teaching and learning environment for cultivating innovative talents, and create a new situation of teaching management to promote the harmonious and scientific development of higher education.

\section{References:}

[1] Jin-gang, Jiang, Wang Bei-yi, Zhang Hui, and Zhang Yong-de. "Cultivation of engineering undergraduate's patent consciousness based on engineering education." In Computer Science \& Education (ICCSE), 2016 11th International Conference on, pp. 763-766. IEEE, 2016.

[2] Herbelin, Bruno, Roy Salomon, Andrea Serino, and Olaf Blanke. Neural Mechanisms of Bodily Self-Consciousness and the Experience of Presence in Virtual Reality Neural Mechanisms of Bodily Self-Consciousness and the Experience of Presence in Virtual Reality. No. EPFL-CHAPTER-220684. De Gruyter, 2016.

[3] Bao, Wenying, and Jianyong Shi. "Entrepreneurship is the driving force of the pension industry development." Studies in Asian Social Science 2, no. 1 (2015): p12. 
[4] Jin-gang, Jiang, Wang Bei-yi, Zhang Hui, and Zhang Yong-de. "Cultivation of engineering undergraduate's patent consciousness based on engineering education." In Computer Science \& Education (ICCSE), 2016 11th International Conference on, pp. 763-766. IEEE, 2016.

[5] Herbelin, Bruno, Roy Salomon, Andrea Serino, and Olaf Blanke. Neural Mechanisms of Bodily Self-Consciousness and the Experience of Presence in Virtual Reality Neural Mechanisms of Bodily Self-Consciousness and the Experience of Presence in Virtual Reality. No. EPFL-CHAPTER-220684. De Gruyter, 2016.

[6] Arling, V., J. Knispel, A. Ritter, and M. Baumann. "Does enhancing consciousness for strategic planning processes support the effectiveness of problem-based learning concepts in biomedical education?." Current Directions in Biomedical Engineering 1, no. 1 (2015): 556-557. 